\title{
Interspecific attack on mice and frogs by golden hamsters (Mesocricetus auratus)
}

\author{
PAUL E. VAN HEMEL \\ Franklin and Marshall College, Lancaster, Pennsylvania 17604
}

\begin{abstract}
When tested for their reactions to mice, most male and female hamsters attacked with a pattern typical of hamster attacks on conspecifics. Females attacked with shorter latency than did males, and the very few hamsters that consistently killed mice were all females. Latencies of attack decreased with repeated testing, even though most attacks were not followed by killing. When tested with frogs, hamsters typically avoided the frogs, although a few showed long-latency attacks and kills. A detailed description of the topography of interspecific attack by hamsters and other closely related groups would be useful as a beginning step in analysis of the function of interspecific attack.
\end{abstract}

Psychologists investigating mouse-killing behavior in rats have been primarily concerned with the causation and ontogeny of the behavior (Polsky, 1975a). Studies that concentrate on such proximate determinants of behavior focus on issues quite different from those raised by studies concerned with ultimate questions about the function, or ecological significance, and the evolution of behavior (Alcock, 1975). Some authors have nonetheless been willing to attribute function to mouse killing, characterizing it as an element of a predatory sequence (O'Boyle, 1974), although it could as easily be considered a form of aggression (Moyer, 1968) which provides an intrinsic source of reinforcement in its species-typical attack pattern (Van Hemel, $1972,1975)$. In the absence of comparative data, statements about the function and evolution of behavior are of questionable validity (Hinde, 1970).

The subjects in studies of interspecific attack in mammals have represented a rather wide range of species (see Polsky, 1975a, b for reviews), but comparative studies (e.g., Kruuk \& Turner, 1967; Thomas, 1969; Wnek \& Leaf, 1973) are rare. Cross-species comparison of behavioral phenotypes is the desirable way to begin species comparisons of similarities and differences in a unit of behavior (Gottlieb, 1976). For such comparison, it is preferable to use species believed to be closely related phylogenetically, thus reducing the likelihood that apparently close similarities between species may turn out to be only parallel evolutionary adaptations to similar environmental demands (Hinde, 1970).

Hamsters and rats are both muroid rodents; hamsters fall in the family Cricetidae, rats in the family Muridae.

The author is grateful to the Franklin and Marshall College Committee on Grants for financial support, to Vincent $M$. Colucci for wondering whether hamsters attack mice, and to Susan B. Van Hemel for helpful criticism of an earlier draft of the paper. Requests for reprints should be sent to Paul E. Van Hemel, Department of Psychology, Franklin and Marshall College, Lancaster, Pennsylvania 17604.
If hamsters attack mice and frogs, as rats do (Bandler \& Moyer, 1970), then a comparison of behavioral phenotypes would be useful as a beginning step for functional analysis. Hamsters are known to attack locusts (Polsky, 1974, 1976) and may catch and consume insects (Jacobs, 1945). There has even been a report of spontaneous attacks by hamsters on mice (Wnek \& Leaf, 1973). The present studies were conducted as a preliminary investigation of the reactions of golden hamsters to mice and frogs. Hamsters of both sexes were used to determine if the reputed greater pugnacity of the female (Short \& Woodnott, 1969) would appear in interspecific encounters.

\section{EXPERIMENT 1}

\section{Method}

Subjects. The subjects were 30 male and 30 female experimentally naive outbred golden hamsters, Mesocricetus auratus, obtained from Lakeview Hamster Colony, Newfield, New Jersey. During a 10-day adaptation period before the experiment and throughout experimental testing, subjects were individually housed in standard suspended rat cages with food and water continuously available.

Procedure. Daily testing for the hamsters' reactions to mice began 10 days after the hamsters' arrival at the laboratory. Each day an adult albino mouse was placed in each hamster's cage. Latencies of any attacks and kills were measured with a stopwatch. Attack latency was defined as the time elapsed between presentation of the mouse and the first seizure of the mouse by the hamster. Killing latency was defined as the time between presentation of the mouse and cessation of movement by the mouse. Except on the final test day for each hamster, bodies of killed mice were removed within $1 \mathrm{~min}$ of the kill, and mice that were not killed were removed after $1 \mathrm{~h}$. Testing continued at daily intervals for each hamster until that animal reached a criterion of consistent reaction, either killing or failing to kill on 10 successive days. On the last test for each animal, the mouse was left with the hamster overnight, whether or not it was killed, and the conditon of the mouse was noted the next day.

\section{Results and Discussion}

For one familiar with studies of mouse killing by rats, several features of the behavior of hamsters toward 
mice were salient. Only 8 of the 60 hamsters killed on 10 successive days to reach criterion, and all 8 of them were females. All of the males and 22 females reached the nonkilling criterion. However, the nonkillers did not ignore the mice. Every hamster attacked at least one mouse, and most hamsters energetically attacked every mouse, persistently biting at flank and tail and chasing when the mouse retreated, a characteristic hamster attack pattern (Lerwill \& Makings, 1971). In one interesting and frequently occurring pattern, the hamster repeatedly attacked from the sideways offensive posture described by Grant and Mackintosh (1963), followed by a lengthy period of lying motionless on its side, with a subsequent resumption of the vigorous chase. Serious or fatal injury to the mouse was the exception rather than the rule, although many hamsters killed some mice and a few were consistent killers. Twenty males and 18 females showed reversals of reaction before becoming consistent killers or nonkillers. Eight of those males and 10 of the females required 15 or more trials to reach criterion. Thirty-two of the 52 nonkillers killed some mice before failing to kill on 10 successive days. It remains to be determined whether the variable reactions of the hamsters to the mice resulted from some particular developmental experience of the hamsters, or from variations in the behavior of the mice in the test situation.

Figure 1 shows the median attack latency during the last 5 days of testing for 23 males and 23 females that each attacked at least 10 mice during the experiment. Analysis of the latencies of the first 10 attacks by these animals showed a significant decline in latency for both sexes (sign tests, $p<.001$ ), but high variability obscured any differences between males and females in latencies of these early attacks. However, the median test (Siegel, 1956) showed that the faster attack by females during the last 5 days, evident in the figure, was reliable $\left(\chi^{2}=5.565, \mathrm{p}<.02\right)$.

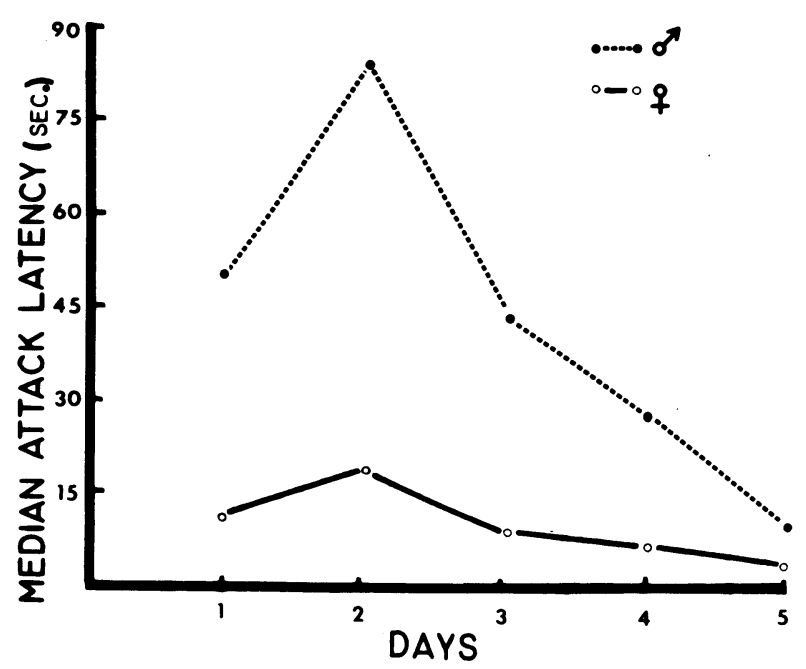

Figure 1. Median attack latency as a function of days during the last 5 days of testing for 23 males and 23 females that each attacked at least 10 mice during Experiment 1.
When mice were left overnight with the hamsters at the end of testing, seven kills occurred after the end of the 1-h test. Counting the eight kills by the consistent killers, that left 15 hamsters in the presence of dead mice for an extended period. Parts of only two of the dead mice were chewed by the next day. Although many hamsters attacked mice, and some killed consistently during the experiment, few ate killed mice when the opportunity was given.

\section{EXPERIMENT 2}

\section{Method}

Subjects. Forty experimentally naive golden hamsters, 20 of each sex, were obtained from Lakeview Hamster Colony. As in the first experiment, they were housed individually with continuous access to food and water before and during experimental testing.

Procedure. Rather than testing to a criterion of consistent killing or nonkilling for 10 successive days, daily for 20 days each hamster received one test of 1-h maximum duration with a stimulus animal. Latencies of any attacks and kills were measured with a stopwatch, and bodies of any killed stimulus animals were removed within $1 \mathrm{~min}$ of the kill. During the first 10 test days, half the males and half the females were tested with frogs, and the other half were tested with mice. For the second 10 test days, hamsters that had been tested with frogs were tested with mice and hamsters that had been tested with mice were tested with frogs, until each hamster had received 10 tests with each of the two types of stimulus animal. Possible order effects in testing were thus counterbalanced, with the exception that one male and one female died of unknown causes before testing was completed. Their data were excluded from the analysis.

\section{Results and Discussion}

Every hamster in this experiment attacked at least half of the 10 mice presented, but only $53 \%$ of them attacked any frogs. Nine males and nine females never attacked any of the 10 frogs presented, and 11 of those hamsters that did attack frogs attacked on only 1 or 2 of the 10 opportunities. Because there were no discernible significant differences in attack latencies between the group tested with frogs first and the group tested with mice first, the data were pooled for further analysis.

Figure 2 shows the median attack latency for males and females during the last 5 days of testing with mice and during the last 5 days of testing with frogs. Latencies of attack on frogs were far longer than the latencies of attack on mice, and the difference was reliable (Mann-Whitney $U$ test, $z=-5.76, p<.001$ ). As in the first experiment, females attacked mice significantly faster than did males (Mann-Whitney U test, $p<.025)$. The apparent differences between males and females in latency of attack on frogs, based on fewer animals attacking, was not statistically reliable.

The behavior of the hamsters in the presence of frogs was highly variable. Initial exploration quickly gave way to avoidance in most cases, with the hamster actively moving to the opposite end of the cage from the frog, often emitting a rasping vocalization in so doing. Several hamsters attacked frogs on 5 or 6 days, and on occasion a sustained biting attack resulted in killing. 


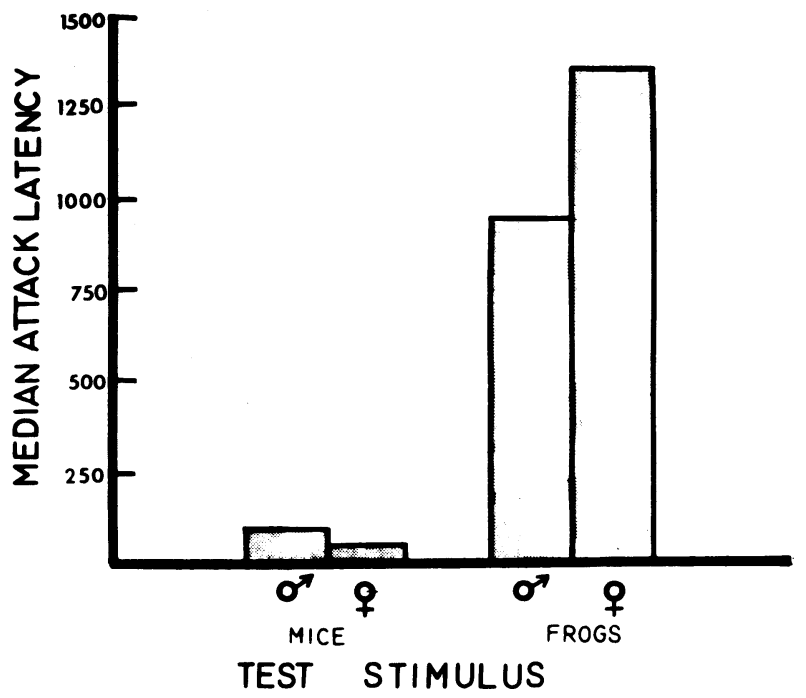

Figure 2. Median attack latency, in seconds, for males and females during the last 5 days of testing with mice and during the last 5 days of testing with frogs in Experiment 2.

However, most of the frogs were not approached or attacked.

\section{GENERAL DISCUSSION}

In these experiments, some hamsters attacked and killed mice and frogs. A greater percentage of hamsters attacked mice than attacked frogs, which is the reverse of the pattern seen when rats are tested with these stimulus animals (Bandler \& Moyer, 1970). Female hamsters attacked mice faster than did males, confirming in interspecific attack the reputed greater aggressiveness of females (Short \& Woodnott, 1969).

With repeated testing, hamsters showed a decrease in latency of attack on mice. A similar decline in latency of attacking or killing has been a consistent finding in studies of mouse killing by rats (Karli, 1956; Myer, 1964; Van Hemel \& Colucci, 1973), and has been taken as evidence for the reinforcing nature of killing behavior. The decrease in latency of attack on mice with repeated testing in the present experiment is particularly noteworthy because a large portion of the attacks were not followed by killing. This finding is consistent with the view that reinforcement is intrinsic to the attack itself (Van Hemel, 1972). However, especially given that the relative size difference between hamsters and mice or frogs is less than that between rats and mice or frogs, it is possible that the attacks by hamsters in these experiments were primarily defensive. Research is needed to determine if hamsters would perform an arbitrary response followed by the opportunity to attack mice.

Because latencies of attack and kill were the primary dependent measures in these experiments, there was no objective record of such interesting aspects of the attack behavior as intensity and duration or accompanying postures and vocalizations. A more detailed analysis of interspecific attack in hamsters, with emphasis on the topograpy of the attack, is needed, along with similar careful analysis of such spontaneously occurring attack patterns in other closely related groups. Then we will be in a position to begin comparing the similarities and differences in controlling stimulus conditions for these behavior patterns among various animal groups, with a view toward understanding the function of these behaviors.

\section{REFERENCES}

Alcock, J. Animal behavior: An evolutionary approach. Sunderland, Mass: Sinauer, 1975.

BANDleR, R., \& MoYer, K. E. Animals spontaneously attacked by rats. Communications in Behavioral Biology, 1970, 5, 177-182.

Gottlieb, G. Comparative psychology. American Psychologist, 1976, 31, 295-297.

Grant, E. C., \& Mackintosh, J. H. A comparison of the social postures of some common laboratory rodents. Behaviour, 1963, 21, 246-259.

Hinde, R. A. Animal behaviour: A synthesis of ethology and comparative psychology. New York: McGraw-Hill, 1970.

JACOBS, D. L. Food habits of the golden hamster. Journal of Mammalogy, 1945, 26, 199.

KARLI, P. The Norway rat's killing response to the white mouse: An experimental analysis. Behaviour, 1956, 10, 81-103.

KruUk, H., \& TuRner, M. Comparative notes on predation by lion, leopard, cheetah, and wild dog in the Serengeti area, East Africa. Mammalia, 1967, 31, 1-27.

LeRwill, C. J., \& Makings, P. The agonistic behaviour of the golden hamster (Mesocricetus auratus). Animal Behaviour, 1971, 19, 714-721.

MOYER, K. E. Kinds of aggression and their physiological basis. Communications in Behavioral Biology, 1968, 2 , 65-87.

MYER, J. S. Stimulus control of mouse-killing rats. Journal of Comparative and Physiological Psychology, 1964, 58, 112-117.

MYER, J. S. Experience and the stability of mouse killing by rats. Journal of Comparative and Physiological Psychology, 1971. 75, 264-268.

O'BoYLE; M. Rats and mice together: The predatory nature of the rat's mouse-killing response. Psychological Bulletin, 1974, 81, 261-269.

Polsky, R. H. Effects of novel environment on predatory behavior of golden hamsters. Perceptual and Motor Skills, 1974, 39, 55-58.

Polsky, R. H. Developmental factors in mammalian predation. Behavioral Biology, 1975, 15. 353-382. (a)

Polsky, R. H. Hunger, prey feeding, and predatory aggression. Behavioral Biology, 1975, 13, 81-93. (b)

Polsky, R. H. Conspecific defeat, isolation/grouping, and predatory behavior in golden hamsters. Psychological Reports, 1976, 38, 571-577.

ShORT, D. J., \& WoodNotT, D. P. The I.A.T. manual of laboratory animal practice and tecinniques. Springfield: Charles C Thomas, 1969.

Siegel, S. Nonparametric statistics. New York: McGrawHill, 1956.

Tномаs, K. Predatory behavior in two strains of laboratory mice. Psychonomic Science, 1969, 15, 13-14.

Van Hemel, P. E. Aggression as a reinforcer: Operant behavior in the mouse-killing rat. Journal of the Experimental Analysis of Behavior, 1972, 17, 237-245.

Van Hemel, P. E. Rats and mice together: The aggressive nature of mouse killing by rats. Psychological Bulletin, $1975,82,456-459$.

Van Hemel, P. E., \& Colucci, V. M. Effects of target movement on mouse-killing attack by rats. Journal of Comparative and Physiological Psychology, 1973, 85, 105-110.

WNEK, D. J., \& LEAF, R. C. Effects of cholinergic drugs on prey-killing by rodents. Physiology and Behavior, 1973, 10, 1107-1113.

(Received for publication September 24, 1976.) 